\title{
EL DERECHO PENAL Y LA LIBERTAD DE EXPRESIÓN EN LAS REDES SOCIALES ${ }^{1}$ Criminal Law and Freedom of Expression on Social Networks
}

\author{
Fabián Andrés Rojas Bonilla ${ }^{2}$ \\ Jenny Catherin García Núñez ${ }^{3}$
}

Fecha de Recepción: 18 de noviembre de 2015

Fecha de Aceptación: 2 de diciembre de 2015

SUMARIO: 1. Introducción; 2. Derecho a la libertad de expresión; 2.1 Alcance otorgado por la Corte Interamericana de Derechos Humanos; 2.2. Alcance otorgado por la Corte Constitucional

Colombiana; 2.2.1 Dimensión del núcleo esencial del derecho a la libertad de expresión;

2.2.2 Límites a la Libertad de Expresión; 2.3 Conclusión Preliminar; 3. Las redes sociales y la libertad de expresión; 3.1 Respecto a los sujetos que intervienen; 3.2 Tipo de discursos que ameritan protección; 3.3 De la responsabilidad en Internet; 3.4 Internet y la libertad de expresión; 3.5 Otras características; 3.6 Reflexión; 4. El uso del derecho penal como limitante a la libertad de expresión en las redes sociales; 4.1 Caracterización del derecho penal en el Estado Social de Derecho; 4.2 El Derecho Penal y la Libertad de Expresión; 5. Conclusión; 6. Referencias Bibliográficas.

\footnotetext{
${ }^{1}$ El presente artículo es derivado de la investigación titulada El Derecho Penal y la libertad de expresión en las redes sociales. Esta investigación fue financiada con recursos propios, y en su desarrollo los autores de este artículo fungieron como investigadores principales.

${ }^{2}$ Abogado y Magister en Derecho (perfil investigativo) de la Universidad Nacional de Colombia. Docente en de las especialización en Derecho Constitucional y Derecho Administrativo de la Universidad Nacional de Colombia, Universidad Santo Tomas y Universidad Militar Nueva Granada. Asesor de la Ministra de Educación Nacional. Correo: faarojasbo14@gmail.com.

${ }^{3}$ Abogada y Especialista en Instituciones Jurídico Procesales y Derecho Constitucional de la Universidad Nacional de Colombia. Aspirante a Magister en Derecho Constitucional de la Universidad Nacional de Colombia. Abogada Asesora Sala Penal del Tribunal Superior de Bogotá. Correo: jcatherin225@hotmail.com
} 


\section{COMO SE CITA ESTE ARTÍCULO (APA 6)}

Rojas Bonilla, Fabián Andrés; García Núñez, Jenny Catherin (2016). El derecho penal y la libertad de expresión en las redes sociales. Revista Jurídica Mario Alario D’Filippo, VIII (15), pág 66-82.

\section{RESUMEN}

Las redes sociales revolucionaron el derecho a la libertad de expresión. Al abrir las puertas a un nuevo modelo comunicativo de corte multidireccional, horizontal, descentralizado, interactivo y con vocación democratizadora normalizaron la posibilidad de difundir ideas y opiniones propias, así como la posibilidad de conocer las de los demás. Ello implica que el alcance tradicional que han dado los juristas a la libertad de expresión deba ser reformulado, pues, entre otras causas, los sujetos de protección han variado, los canales de difusión son múltiples y el público que accede a los contenidos es muy variado. Así mismo, las formas de restricción y afectación legítima a la garantía deben reformularse. Este artículo tratará de responder al siguiente interrogante: ¿Es el derecho penal un mecanismo adecuado para regular el ejercicio del derecho a la libertad de expresión en Internet?

\section{PALABRAS CLAVES}

Libertad de expresión, Internet, derecho penal, redes sociales.

\section{ABSTRACT}

Social networks revolutionized the freedom of speech. Once opened the doors of this new communication model, which is characterized by being multidirectional, horizontal, decentralized, interactive and with democratizing vocation, it has been normalized the possibility of disseminate personal ideas and opinions as well as the opportunity of making known other points of view. This involves that the traditional scope provided by the jurist respect freedom of speech should be reformulated, as, among another important aspects, the subjects of protection had changed, the communication canals are multiples and the public which access each contents of guarantee is very diverse and complex. Similarly, all forms of affectation and legitimate restriction of liberty must be redefined. This paper will try to answer the following question: it is the criminal law the appropriate mechanism for regulate the freedom of speech at the Internet?

\section{KEYWORDS}

Freedom of speech, Internet, criminal law, social networks. 


\section{INTRODUCCIÓN}

En este documento se pretende reflexionar sobre el uso del derecho penal en los delitos que involucran la libertad de expresión en las redes sociales. El tema resulta atractivo y novedoso para la ciencia jurídica debido a, por lo menos, dos razones. La primera de ellas es que el tema involucra la tensión entre varios derechos fundamentales, a saber: la libertad de expresión y la libertad individual, de un lado, y el derecho a la honra, al buen nombre y a la intimidad, del otro. La segunda razón tiene que ver la gran actualidad que significan las redes sociales y las nuevas tecnologías en las interacciones sociales, de la que, por supuesto, no puede ser ajena la disciplina del derecho.

El primer punto de partida será reconocer que la libertad de expresión adquiere un nuevo enfoque con la expansión de Internet. Así, no resulta extraño que uno de los principales medios por los que las personas adquieren información sean las redes sociales, las cuales, fieles a las filosofía web 2.0, no realizan ningún tipo de control inicial a los contenidos que los usuarios suben a la red (Cotino, 2011). Ello implica que la opinión, pensamiento y/o idea de una persona que antes era invisibilizada porque no podía acceder a los tradicionales medios de comunicación o, en el mejor de los casos, accedía con un filtro que realizaba la televisión, radio o periódico, hoy en día se puede difundir y conocer de manera inmediata en el mundo con un solo clic, sin que sobre esta recaiga control previo alguno.

Internet revolucionó el mundo en cuanto al tratamiento de información. Pareciera que lo que muchos han Ilamado el cuarto o quinto poder del Estado (Ramonet, 2016), hoy por hoy, enfrenta una realidad que lo enviste de manera tal que su esencia misma se desdibuja. Y si bien es cierto que Internet, al igual que la radio, la televisión o los periódicos, solo es un medio o canal por el que las personas se comunican (lo que haría pensar a algunos que Internet no hace parte de lo que se denomina el núcleo esencial del derecho a la libertad de expresión), también lo es que la popularidad de dicho medio hace que la circulación de los discursos se torne más libre y pública. Así las cosas, la posibilidad de manipulación de información por unos pocos (quienes ostentan el monopolio de los medios) parece reducirse sustancialmente.

Ello no significa que Internet sea la panacea jurídica de la libertad de expresión. Las nuevas tecnologías también imponen retos al derecho. El concepto de aplicación territorial de la ley, por ejemplo, parece desaparecer absolutamente en la red, lo cual se ha traducido en que algunas de las conductas punibles, de alta reprochabilidad social, queden en la impunidad. Ejemplo de ello son los atentados contra la integridad sexual de niños y niñas, los discursos de racismo, odio, xenofobia, etc. Por esta última razón, acierta el profesor Cotino cuando sostiene que es necesario legislar en el asunto, con la condición de que dicha legislación se realice de manera adecuada. El ejercicio de los derechos fundamentales de las personas debe estar garantizado por el Estado en Internet. Lo 
anterior amerita especial reflexión: primero, por regla general, se debe garantizar el pleno ejercicio de la libertad de expresión de las personas, sin importar del tipo de discurso que se trate, pues ello hace parte del derecho al libre desarrollo de la personalidad. Segundo, debe existir una garantía especial cuando se trate de discursos especialmente protegidos, tal como es el caso del discurso político, pues ello garantiza el modelo democrático en las sociedades contemporáneas. Tercero, lo único que justificaría una restricción a un derecho fundamental sería una razón de peso mayor como, por ejemplo, la afectación a otro derecho fundamental o a un asunto racional de interés general (Cotino, 2009). Pero ¿qué tipo de restricciones sería legítimo adoptar? ¿Es el derecho penal un mecanismo adecuado para regular el ejercicio de derechos fundamentales en Internet? El siguiente documento pretende resolver este último interrogante a la luz de lo que se debe entender por derecho penal en un Estado Social y Democrático de Derecho.

\section{DERECHO A LA LIBERTAD DE EXPRESIÓN}

A continuación se explicará el alcance del derecho a la libertad de expresión en el Sistema Interamericano de Derechos Humanos y en el Derecho Colombiano. Para ello se han seleccionado algunas sentencias hito en la materia, las cuales son apenas una aproximación a un tema que seguramente amerita un estudio de línea jurisprudencial mucho más detallado y profundo que el que aquí se logra por temas de brevedad y espacio. El propósito será el de comparar los dos sistemas y determinar el alcance del derecho a la libertad de expresión y las limitaciones legítimas que eventualmente se pueden interponer.

\subsection{ALCANCE OTORGADO POR LA CORTE INTERAMERICANA DE DERECHOS HUMANOS}

La libertad de expresión es un derecho consagrado en diversos instrumentos de derechos humanos ${ }^{4}$. En el caso de la Convención Americana Sobre Derechos Humanos (en adelante la $\mathrm{CADH})$, el artículo 13 establece:

Toda persona tiene derecho a la libertad de pensamiento y de expresión. Este derecho comprende la libertad de buscar, recibir y difundir informaciones e ideas de toda índole, sin consideración de fronteras, ya sea oralmente, por escrito o en forma impresa o artística, o por cualquier otro procedimiento de su elección [...] (1969, pag. 6).

En una línea jurisprudencial uniforme, la Corte Interamericana de Derechos Humanos (en adelante la CorteIDH) ha sostenido que la disposición convencional garantiza dos dimensiones: a) La primera permite al individuo manifestarse a través de sus opiniones,

\footnotetext{
${ }^{4}$ Véase: Declaración Universal de Derechos Humanos (1948), artículo 19; El Pacto Internacional de Derechos Civiles y Políticos (1966) en su artículo 19 numeral 2; la Declaración Americana de los Derechos y Deberes del Hombre de 1948, en su artículo iv; la Convención Americana Sobre los Derechos Humanos (1969) y la Convención Europea para la Protección de los Derechos Humanos y las Libertades Fundamentales (1950), artículo 10.
} 
ideas y/o pensamientos y b) la segunda hace referencia a la posibilidad de la sociedad de buscar, recibir y difundir información de toda índole, sin consideración de fronteras o medios. La Corte ha mencionado que las dos dimensiones a las que se acaban de hacer referencia son indivisibles (CorteIDH Caso "la última tentación de Cristo Vs. Chile [2001]; Caso Herrera Ulloa Vs. Costa Rica [2004] ; Caso Ivcher Broentein Vs. Perú [2001]) Lo anterior implica, entre otros aspectos, que cuando se limita el pleno ejercicio del derecho de libertad de expresión a una persona natural o jurídica, estas últimas representadas tradicionalmente en los medios de comunicación, indirectamente se está limitando el derecho a la sociedad de recepcionar información.

Ahora bien, vale la pena precisar que el principal objetivo de tutelar este derecho consiste en generar espacios de debate y discusión, así como promover la investigación de asuntos públicos que permitan a los ciudadanos formarse una opinión y exigir responsabilidad y transparencia en el ejercicio de funciones públicas (CortelDH Caso Eduardo Kimel Vs. Argentina [2008]; Caso Ricardo Canese Vs. Paraguay [2004]) En tratándose de funcionarios públicos las manifestaciones que se hacen son discursos especialmente protegidos porque tienen que ver con el ejercicio del poder público (CortelDH Caso Ricardo Canese Vs. Paraguay [2004]) Con base en lo anterior, la CorteIDH ha resaltado la importancia de los medios de comunicación en una sociedad libre y democrática, puesto que aquellos permiten difundir información de interés público, generar espacios de debate y discusión, promover la investigación de asuntos públicos que permiten a los ciudadanos formarse una opinión y, además, exigir responsabilidad y transparencia en el ejercicio de funciones y obligaciones públicas (Corte IDH Caso Ivcher Bronstein Vs. Perú [2001]; Caso Herrera Ulloa Vs. Costa Rica [2004]; Caso Palamara Iribarne Vs. Chile [2005]; Caso Eduardo Kimel Vs. Argentina [2008] $)^{5}$ En este mismo sentido se ha manifestado el Tribunal Europeo de Derechos Humanos (T.E.D.H., Case of Incal Vs. Turkey [1998]; Case of Bowman Vs. The United Kingdom [1998]).

En conclusión, la CortelDH ha concentrado sus esfuerzos en brindar protección para la emisión de opiniones, ideas y/o pensamientos propios y, adicionalmente, en garantizar la búsqueda de opiniones, ideas y/o pensamientos ajenos. Tradicionalmente dichas funciones (la de emitir y la de buscar información) ha estado en cabeza de los medios de comunicación tradicionales: televisión, radio y prensa escrita. Dicha tendencia ha cambiado con la existencia de Internet. Un ejemplo de lo anterior es la existencia, cada vez más popularizada, de los "youtubers", quienes no requieren del ejercicio profesional del periodismo para emitir opiniones e influenciar en el pensamiento de muchos de sus seguidores. De allí que la mayoría de casos que ha conocido el Tribunal seguramente deberán adaptarse a estas nuevas maneras de difundir y buscar información.

${ }^{5}$ Véase también: Organización de los Estados Americanos (1994) Informe anual de la Comisión Interamericana de Derechos Humanos 1994. Recuperado de: https://www.cidh.oas.org/annualrep/94span/indice.htm 


\subsection{ALCANCE OTORGADO POR LA CORTE CONSTITUCIONAL COLOMBIANA}

\subsubsection{Dimensión del núcleo esencial del derecho a la libertad de expresión}

Al igual que el artículo 13 de la $\mathrm{CADH}$ en el Sistema Interamericano de Derechos Humanos, el artículo 20 de la Constitución Política de Colombia (1991) es la disposición que consagra el derecho a la libertad de expresión en el derecho interno colombiano. Allí se consagra que:

Se garantiza a toda persona la libertad de expresar y difundir su pensamiento y opiniones, la de informar y recibir información veraz e imparcial, y la de fundar medios masivos de comunicación. Estos son libres y tienen responsabilidad social. Se garantiza el derecho a la rectificación en condiciones de equidad. No habrá censura.

La Corte Constitucional colombiana ha interpretado y definido el alcance de la libertad de expresión. Así, ha manifestado que dicha garantía constitucional no es un derecho absoluto, por lo que existen casos en los que el mismo puede llegar a ser restringido. Dichas restricciones deben presentarse de manera excepcional, pues se entiende que la libertad de expresión involucra el ejercicio de derechos políticos necesarios en una democracia (Carbonell, 2011) y derechos individuales como el libre desarrollo de la personalidad (Chirino, 2014). Así las cosas, la Corte ha manifestado que en cada caso en concreto se debe establecer si las restricciones que se imponen son adecuadas, necesarias y proporcionales. Un ejemplo de dicha postura se encuentra en la sentencia T-1037 de 2010, providencia en la que la Corte conoció el caso de unos manifestantes de un municipio colombiano que acudían al megáfono para promover un proceso revocatorio del mandato del Alcalde y a quienes se les prohibió el uso del mismo aduciendo razones de orden público. El problema jurídico, en palabras de la Corte, fue el siguiente: “¿Un municipio vulnera los derechos fundamentales a la libertad de expresión, a la información y al pluralismo informativo de un grupo de veedores ciudadanos, al prohibir el perifoneo por megáfono de una campaña de revocatoria de mandato, sobre la base de argumentos de seguridad y alteración de orden público?" (Corte Constitucional, 2010).

El mencionado fallo judicial, ratificador de línea jurisprudencial (López, 2006), compiló la doctrina que sobre el asunto tiene el tribunal constitucional colombiano. Así, es pertinente recordar que el derecho a la libertad de expresión es un derecho fundamental, y como tal, resulta inalienable, imprescriptible e inviolable. Lo anterior no significa que sea un derecho absoluto, puesto que, como todo derecho, tiene límites los cuales deben observarse conforme al caso específico. En la providencia judicial se ratificó el derecho político de los manifestantes a promover la revocatoria del mandato a la alcaldesa del municipio. Adicionalmente, se ha establecido que dicho derecho comprende la garantía jurídica de informar y ser informado veraz e imparcialmente. Ello significa que el conocimiento que se comunica, o que se adquiere por sí mismo, debe ser protegido por el Estado, pero siempre y cuando no vulnere valores sustanciales como el buen nombre, 
la intimidad, el orden público, y el bien común, que es la expresión del interés general (Corte Constitucional colombiana, 1993) El aspecto de la información racionalmente veraz comporta la exigibilidad de que la persona que informa haya agotado un proceso de verificación (Corte Constitucional Colombiana, 2000).

\subsubsection{Límites a la Libertad de Expresión}

Hasta el momento se ha descrito lo que podría catalogarse como "la comprensión de la Corte Constitucional Colombiana sobre el núcleo esencial del derecho a la libertad de expresión". Se procede, entonces, a mencionar los límites legítimos a dicho derecho que se han reconocido en el ámbito nacional. Tal como se adelantó al inicio de este acápite, la Corte estima que la libertad de expresión no es un derecho absoluto, puesto que su ejercicio debe comprender un respeto por el derecho de los demás y debe desarrollarse con observancia del orden jurídico. Tradicionalmente se ha entendido que los derechos que se pueden ver afectados con un uso ilegitimo del derecho a la libertad de expresión son aquellos como la honra, el buen nombre o la intimidad y, de manera más general, el interés general, la protección de la seguridad y el orden público, de la salud pública y de la moral pública, etc. Teniendo ello claro, la Corte, siguiendo de cerca las experiencias del derecho foráneo, ha establecido como subregla de derecho la prohibición a los discursos de odio, los que promuevan la guerra o la violencia, los que impulsen la comisión de delitos como la pornografía infantil o el genocidio, etc. Los anteriores son discursos que se consideran per se negativos y que no ameritan ser tutelados en ningún momento y bajo ninguna circunstancia. Ahora bien, en lo que a los demás discursos atañe, la Corte ha considerado que cualquier limitación que se pretenda realizar al derecho debe tener en cuenta los siguientes requisitos:

a) Estar prevista de manera precisa y taxativa por la ley: Con ello lo que se pretende es materializar el postulado del Estado de Derecho, el cual se edifica a partir del principio de legalidad como condición y garantía para el legítimo uso del poder (Jaramillo, 2012).

b) Perseguir el logro de ciertas finalidades imperativas: Por tratarse de una afectación a un derecho fundamental, las restricciones deben apelar a una finalidad.

c) Ser necesarias para el logro de dichas finalidades: Los límites que se impongan deben requerirse para lograr la finalidad.

d) Ser posteriores y no previas a la expresión: Este requisito se encuentra íntimamente relacionado con el postulado de legalidad de los límites y las sanciones.

e) No constituir censura en ninguna de sus formas: Ello significa que la autoridad que imponga los límites debe guardar neutralidad frente al contenido de la expresión que se limita.

f) No incidir de manera excesiva en el ejercicio de este derecho fundamental, es decir, ser_proporcionada: Las restricciones que se imponen no deben resultar de mayor envergadura y gravedad que las consecuencias que derivarían de no imponerlas (Corte Constitucional, 2007). 
Pero más aún, la misma Corte Constitucional ha reconocido que, por lo que se denomina el bloque de Constitucionalidad, sólo es pertinente restringir dicho derecho fundamental cuando se trate de las finalidades establecidas en el artículo 19 del Pacto Internacional de Derechos Civiles y Políticos (1966) y el 13 de la Convención Americana de Derechos Humanos (1969). Específicamente, el último de los artículos mencionados señala:

(i) El ejercicio del derecho previsto en el párrafo 2 de este artículo entraña deberes y responsabilidades especiales. Por consiguiente, puede estar sujeto a ciertas restricciones, que deberán, sin embargo, estar expresamente fijadas por la ley y ser necesarias para: (a) Asegurar el respeto a los derechos o a la reputación de los demás; (b) La protección de la seguridad nacional, el orden público o la salud o la moral públicas. (ii) El ejercicio del derecho previsto en el inciso precedente no puede estar sujeto a previa censura sino a responsabilidades ulteriores, las que deben estar expresamente fijadas por la ley y ser necesarias para asegurar: a. el respeto a los derechos o a la reputación de los demás, o b. la protección de la seguridad nacional, el orden público o la salud o la moral públicas. (iii) Los espectáculos públicos pueden ser sometidos por la ley a censura previa con el exclusivo objeto de regular el acceso a ellos para la protección moral de la infancia y la adolescencia, sin perjuicio de lo establecido en el inciso 2 (Subrayados y numeración míos).

\subsection{CONCLUSIÓN PRELIMINAR}

Una vez expuestos los puntos principales sobre el núcleo esencial del derecho a la libertad de expresión, tanto en el Sistema Interamericano de Derechos Humanos como en el sistema colombiano, resulta plausible sostener que el núcleo esencial de dicho derecho no difiere en gran medida en uno y otro sistema. No obstante lo anterior, este trabajo no puede desconocer que el derecho a la libertad de expresión es uno de los temas que más se discuten en el plano de los derechos humanos. De hecho, pareciera que conceptualmente existe consenso sobre los parámetros que deben tener en cuenta las entidades estatales al momento de garantizar el pleno goce de ese derecho y de cuáles son los requisitos para limitarlo, sin embargo, en la práctica, ello no aparece ni funciona pacífica y/o adecuadamente. Ello puede obedecer a que se encuentran en juego intereses de poder que hacen que los actores traten de interpretar las cláusulas de la manera que les resulte más favorable a sus propios intereses. El manejo del discurso también es un manejo del poder (Foucault, 1970) Es más, el reconocimiento de lo que se denomina como el margen nacional de apreciación de los Estados (Barbosa, 2012) es una clara muestra de las dificultades de aplicación del sistema. Estas dificultades se potencializan en el derecho internacional, entre otras razones, por la soberanía de los Estados y por los problemas que evidencia el lenguaje desde los estudios de filosofía analítica del siglo XX.

\section{LAS REDES SOCIALES Y LA LIBERTAD DE EXPRESIÓN}

Tal como se avizoraba en la parte inicial de este documento, el surgimiento de las redes sociales lleva consigo una revolución en las formas como se ejerce la libertad de expresión. Gracias a las redes sociales la libre circulación de ideas y opiniones se ha 
incrementado de manera exponencial. Ello demanda un estudio jurídico del asunto. Las dinámicas propias del funcionamiento de las redes sociales, denominadas como filosofía web 2.0, se caracterizan porque el usuario crea una nueva subjetividad en la medida que construye la información que él mismo está interesado en publicar y accede a la que le resulta llamativa. Estos procesos, sin lugar a dudas, tienen repercusiones en el mundo jurídico y en la forma tradicional de entender la libertad de expresión.

\subsection{RESPECTO A LOS SUJETOS QUE INTERVIENEN}

Un buen principio es hablar de los sujetos de protección. En la forma tradicional de ejercer el derecho a la libertad de expresión las personas que ameritaban algún tipo de tutela jurídica eran los periodistas y, muy excepcionalmente, algunos políticos, pues estos dos grupos poblacionales eran quienes tenían interés en que cierto tipo de información estuviera divulgada. Ahora, con espacios como Facebook, Twitter, Instagram, etc., las personas que tienen la potestad de expresar sus ideas y que están interesados en que dicha potestad se garantice plenamente son todos los usuarios de las redes sociales. En solo Facebook dicho número ascendió a 1060 millones de usuarios a nivel mundial en $2013^{6}$ No solamente los periodistas y políticos eran objetos de protección jurídica sino que, además, también eran susceptibles de ser sujetos pasivos de las acciones jurídicas correspondientes cuando alguna autoridad consideraba que se había incurrido en una falsedad o se había vulnerado el derecho de otra persona como ocurría, por ejemplo, con el buen nombre, la honra o la intimidad, etc. Ahora, con las redes sociales, cualquier sujeto es susceptible de ser judicializado por la afectación a un derecho ajeno. Es decir, con la popularización de Internet se ha abierto el ámbito de protección de la libertad de expresión, pues ha pasado de ser un derecho tradicionalmente garantizado a los periodistas y los políticos para, en su lugar, ser un derecho de susceptible de protección a cualquier usuario de la web. En contraste, también las personas que se pueden ver afectadas por restricciones ilegitimas han aumentado.

\subsection{TIPO DE DISCURSOS QUE AMERITAN PROTECCIÓN}

Otro aspecto que resulta interesante analizar es el de los discursos que ameritan protección por parte de las autoridades. Lo que tradicionalmente se ha dicho es que el discurso político y el que permite el pleno desarrollo de la personalidad son susceptibles de tutela estatal. Ello pasaba antes del surgimiento de las redes sociales y ahora, con su existencia, parece que dichos discursos se encuentran reforzados en la medida que la dinámica misma de las redes sociales impone una mayor publicidad.

Tal como se mencionó con antelación, tradicionalmente los discursos estaban controlados por un editor de revista, un guionista de televisión o un programador de radio. El control

${ }^{6}$ Candelas, R. (2013) 1060 millones de usuarios en Facebook en el 2013. Merca2.0. Recuperado de: https://www.merca20.com/ facebook-2013-1060-millones-de-usuarios/ 
sobre los discursos iba desde el momento que se seleccionaba al periodista o presentador, se le indicaba los temas sobre los que hablaría y, en cada intervención, se revisaba el discurso. Los anteriores controles no existen en la web. Allí opera la plena libertad del usuario. La doble cara de la moneda de la libertad implica menor posibilidad de censura $y$, a su turno, mayor probabilidad de un ejercicio abusivo de la libertad para expresar ideas. La dificultad para el control efectivo de los discursos prohibidos es un ejemplo claro de la libertad que se ha configurado en Internet y que impide limitaciones efectivas.

\subsection{DE LA RESPONSABILIDAD EN INTERNET}

Otro problema arraigado en la masiva difusión de Internet se centra en la atribución y persecución de responsabilidad por la difusión de contenidos ilícitos, sea esta civil, administrativa o penal. Inicialmente se plantean unas dificultades materiales: por un lado, las limitaciones del derecho nacional para perseguir contenidos ilícitos por estar ubicados fuera del ámbito territorial, por otro, la integración del contenido normalmente se hace en el anonimato, por ende, conocer el número IP puede no ser suficiente para determinar la identidad del sujeto y, por último, la autoría y difusión colaborativa de los contenidos de la web 2.0 conlleva que sea casi imposible determinar el responsable de su contenido y difusión. Aparejado a ello existe un límite de carácter jurídico, debido a la grave insuficiencia normativa relacionada con el comercio electrónico. De acuerdo con la directiva 2000/31/CE de la Unión Europea, el prestador de servicios de internet no tiene un deber de vigilar los contenidos que transmite (artículo 15) ni es responsable de los mismos si son ilícitos, pero sí tiene el deber de retirar o bloquear los contenidos cuando las autoridades le comunican la ilicitud (Cotino, 2009).

\subsection{INTERNET Y LA LIBERTAD DE EXPRESIÓN}

Internet ha establecido una nueva forma de comunicación y de difusión de información; se ha abierto como un nuevo espacio social con la connotación de ser virtual. Este se presenta como un espacio propicio para el desarrollo de las libertades públicas, entre ellas, la libertad de expresión. Al abrirse las puertas a este nuevo modelo comunicativo de corte multidireccional, horizontal, descentralizado, interactivo y con vocación democratizadora, la libertad de expresión adopta connotaciones diferentes en este ámbito.

Internet se ha expandido de tal manera, y la prestación de servicios es de tan diversa índole, que no toda actividad realizada a través de este medio debe ser considerada como un supuesto de expresión de esta libertad y no en todos los campos queda amparada la misma, así como no en todos los supuestos se ve afectada esta garantía. Según el profesor Cotino (2011) para determinar aquellos supuestos en los que se pueda ver comprometido el ejercicio de la libertad de expresión a través de Internet, será necesario distinguir el tipo de actividad o de servicio que se realiza o al que se dedica una

determinada página web. Se deberán distinguir aquellas páginas dedicadas a la "difusión 
de información"7 que de manera intrínseca supondrían un ejercicio de la libertad de expresión, independientemente de si ellas representan un beneficio económico o suponga el ejercicio de una actividad económica y, por otro lado, páginas web que se dedican a la "prestación de servicios telemáticos"8 los cuales quedan al margen de esta libertad pública.

\subsection{OTRAS CARACTERÍSTICAS}

Finalmente, uno de los mayores problemas que se presenta en este asunto es que no se encuentra mayor regulación y por lo general son las instituciones particulares o públicas quienes resultan decidiendo como mejor les parece. Tal es el caso, por ejemplo, de la sentencia T-713 de 2010, en la cual se conoció el caso de un estudiante al que se le impuso una sanción por haber participado en grupo de una red social que elevaba improperios contra la rectora de la institución (Corte Constitucional, 2010). La participación en grupos de las redes sociales está amparada, sostienen algunos, entre otros, por el derecho fundamental a la libertad de expresión y la regulación de lo que puede hacerse o no en estos espacios escapa prima facie al ámbito de los reglamentos escolares (Roa, 2014).

\subsection{REFLEXIÓN}

Lo anterior demuestra que el surgimiento de las redes sociales lleva consigo un cambio en la forma tradicional de comprender la libertad de expresión. No significa ello que después del surgimiento de las redes sociales haya emergido el derecho a la libertad de expresión de las personas que no son periodistas ni políticos. No. Este derecho ha existido desde mucho tiempo atrás. El gran cambio de las redes sociales consiste en masificar la conciencia sobre dicho derecho y convertir a todos en seres con voz en los más diversos asuntos.

En los términos de Upegui Mejía esta caracterización nos permite afirmar que sería inadecuado e insuficiente hacer una valoración jurídica de tales hechos sin considerar, por ejemplo, el carácter de las redes sociales, los nuevos significados que pueden tener los ejercicios de comunicación que suceden en su seno, el tipo de subjetividad que se ha creado a partir de la existencia de las redes sociales, y el tipo de espacio en donde se ejerce la actividad, el cual, por demás, difícilmente podría ser catalogado como privado o público siguiendo criterios clásicos (2010).

Bajo dichos presupuestos, el núcleo esencial sobre el derecho a la libertad de expresión en las redes sociales amerita tener en cuenta la complejidad del campo en el cual se desarrolla. Una red social, por ejemplo, es un espacio en el que las personas se pueden

\footnotetext{
${ }^{7}$ Por ejemplo aquellas web que prestan servicios de provisión de instrumentos de búsqueda, acceso y recopilación de datos o de enlaces a otros sitios de Internet.

${ }^{8}$ Páginas dedicadas al comercio electrónico de prestación de servicios telemáticos como "gestiones bancarias", por ejemplo.
} 
encontrar con información de la más variada índole y son ellas quienes deciden cuál leen y cuál no. Una red social depende del perfil de cada usuario. Una pregunta que vale la pena hacerse es si la persona que publica contenido inapropiado, pero solo se lo permite observar a tres o a cuatro amigos cercanos, debe ser tratado de la misma manera que la persona que se lo publica a los 1060 millones de usuarios de Facebook.

\section{EL USO DEL DERECHO PENAL COMO LIMITANTE A LA LIBERTAD DE EXPRESIÓN EN LAS REDES SOCIALES}

\subsection{CARACTERIZACIÓN DEL DERECHO PENAL EN EL ESTADO SOCIAL DE DERECHO}

Los profesores Ferrajoli (2006) y Mir Puig (1994), máximos exponentes del garantismo penal contemporáneo, enseñan que en el derecho penal debe materializar el postulado de dignidad humana, a partir del cual se edifica el Estado Social y Democrático de Derecho. Así mismo, en la medida que el derecho penal es el más severo y grave de todas las ramas del derecho, pues sus penas muchas veces van en contra del principio de dignidad humana por atentar contra la libertad individual, su aplicación debe ser mínima. En otras palabras, la creación de delitos y la imposición de penas deben obedecer al principio de mínima injerencia del derecho penal en los asuntos públicos. La anterior es la máxima del derecho penal como ultima ratio.

Muchos han sido los intentos de humanizar los delitos y las penas. Desde la famosa obra del profesor Beccaria (1764) De los delitos y de las penas, pasando por el programa criminal de Carrara (1859) hasta llegar a Ferrajoli y Mir Puig, el derecho penal contemporáneo se ha preocupado por rescatar el lado humano de las formas de castigo. Así, no resulta extraño que en el campo de la criminología existan corrientes que aboguen radicalmente por un abolicionismo carcelario.

\subsection{EL DERECHO PENAL Y LA LIBERTAD DE EXPRESIÓN}

Las principales críticas en contra del uso del derecho penal como castigo por el uso indebido del derecho a la libertad de expresión provienen de los profesionales del periodismo y de los activistas políticos (no demorarán los reclamos de los usuarios de redes sociales). Los primeros sostienen que tipos penales como la injuria y la calumnia deberían desaparecer de la legislación penal para ser tratadas por otras ramas del derecho, tales como el derecho administrativo o el derecho civil y, con ello, garantizar que el derecho penal sea realmente de ultima ratio. Los segundos demandan que a la luz del principio de orden público existe una sistemática represión a la protesta social, la cual proviene, preferentemente, del gobierno de turno que no admite reproche a sus labores (Gamarra, 2010).

Las anteriores críticas han sido aceptadas parcialmente por la Corte Constitucional colombiana, quien en sentencia C-489 de 2002 afirmó: 
El derecho penal comporta una valoración social en torno a los bienes jurídicos que ameritan protección penal, las conductas susceptibles de producir lesiones en tales bienes, el grado de gravedad de la lesión que dé lugar a la aplicación del ius puniendi, y el quantum de la pena que deba aplicarse [...] En este contexto, el legislador puede optar por prescindir de la protección penal, cuando considere que basta con los mecanismos previstos en otros ordenamientos. O puede atenuar las medidas de protección penal, restringiendo el ámbito del tipo penal, o reduciendo el quantum de la pena, o, en fin, excluir la responsabilidad o la punibilidad por consideraciones de tipo preventivo. $Y$ todo dentro de la valoración, también, de la medida en que se estima vulnerado el bien jurídico protegido. En particular, resulta admisible que frente a las conductas que afectan la integridad moral, se considere que no es necesario una ulterior protección penal cuando el derecho se ha restablecido a través de la retractación en las condiciones y con las características que al efecto haya previsto la ley (Corte Constitucional, 2002).

\section{CONCLUSIÓN}

Corolario de todo lo anterior se estima que el derecho penal no resulta ser un mecanismo adecuado para atender los eventuales abusos del derecho a la libertad de expresión en las redes sociales cuando se tratan de discursos políticos o del libre desarrollo de la personalidad, ya que, a menos que se evidencie una capacidad de persuasión en los discursos prohibidos de la misma magnitud que podría acontecer en la plaza pública, los bienes e intereses sociales no se ven afectados en la misma medida. No sería pertinente, por ende, apelar a dicha rama del derecho para pretender su corrección. Menos aún si se trata de un Estado Social de Derecho que reconoce al derecho penal como la ultima ratio para resolver los conflictos sociales.

Además, los beneficios que aportan en una sociedad democrática las redes sociales deben ser observados de una manera altamente positiva, pues ellas garantizan que las personas hagan parte de los debates públicos y se puedan formar una idea sobre lo que debe ser una buena o mala forma de organización estatal. No está de más recordar que el principio democrático está ampliamente reconocido como un eje fundamental que requiere especial protección, fomento y divulgación del Estado. Ello se materializa cuando se indica que todo ciudadano tiene derecho a participar en la conformación, ejercicio y control del poder político y que es ideal fomentar "prácticas democráticas para el aprendizaje de los principios y valores de la participación ciudadana" (Consejo Académico Universidad Javeriana, 2003).

En ese orden de ideas, el uso del derecho penal en los discursos políticos y de libre desarrollo de la personalidad en las redes sociales no atiende a los postulados que se han reconocido como necesarios para limitar el ejercicio del derecho fundamental a la libertad de expresión, particularmente el de la proporcionalidad. No significa lo anterior que dichas conductas no deban ser perseguidas por el Estado, simplemente se trata de reconocer que el derecho penal no es el adecuado y que se pueden acudir a otros procedimientos, tales como el administrativo y/o civil. 
Lo anterior no descarta que cuando existan discursos prohibidos, tales como los de promoción de la pornografía infantil, los discursos de odio o xenofobia; el derecho penal deba actuar; sin embargo, deberá ser un derecho que reconozca las particularidades y necesidad de una sociedad globalizada e influenciada por las TIC.

\section{REFERENCIAS BIBLIOGRÁFICAS}

Barbosa Delgado, F. (2012) El margen nacional de apreciación y sus límites en la libertad de expresión. Análisis comparado de los sistemas europeo e interamericano de derechos humanos. Bogotá: Universidad Externado de Colombia.

Beccaria, C. (2012) De los delitos y de las penas. 3a Edición, 6a reimpr. Bogotá: Ed. Temis.

Carbonell, M. (2011) El fundamento de la libertad de expresión en la democracia constitucional. En: Libertad de expresión: debates, alcances y nueva agenda. María Paz Ávila Ordoñez, Ramiro Ávila Santamaria y Gustavo Gómez Germano (Ed.) Quito. Recuperado de: http://unesdoc.unesco.org/images/0021/002156/215627s.pdf

Carrara, F. (1947) Programa de Derecho Criminal. Buenos Aires: Depalma.

Chirino Sánchez, A. (2011) Libertad de expresión y Ley Penal. En: Libertad de expresión: debates, alcances y nueva agenda. María Paz Ávila Ordoñez, Ramiro Ávila Santamaria y Gustavo Gómez German (Ed.) Quito. Recuperado de: http://unesdoc.unesco.org/ images/0021/002156/215627s.pdf

Cotino Hueso, L. (2009) El problema de la responsabilidad por los contenidos ilícitos en la web 2.0 y algunas propuestas de solución. Ponencia. Institute of Law and Technology (IDT), Universidad Autónoma de Barcelona, 18 de septiembre de 2009, Sala Marie Curie, Centro de Convenciones y Congresos, Hotel Sehrs Campus.

. (2011 Libertades de expresión e información en Internet y las redes sociales: ejercicio, amenazas y garantías, PUV (Publicaciones de la Universidad de Valencia). Editor. Libro en soporte electrónico. ISBN 978-84-694-0081-4. Valencia. 52- 87.

Ferrajoli, L. (2006) Derecho y Razón teoría del garantismo penal. 8a Edición. Madrid: Trotta.

Foucault, M. (1970) El orden del discurso. Trad. Alberto González Troyano (1992). Buenos Aires. Tusquets.

Gamarra Herrera, R. (2010) Libertad de expresión y criminalización de la protesta social. En: ¿Es legítima la criminalización de la protesta social? Derecho Penal y Libertad 
de Expresión en América latina. Eduardo Bertoni (Compilador). Universidad de Palermo.

Jaramillo Jaramillo, C. (2012) El precedente judicial en Colombia. Pontifica Universidad Javeriana. Ibañez.

López Medina, D. (2006) El Derecho de los jueces.2a Edición. Bogotá: Legis.

Mir Puig, S. (1994) El Derecho Penal en el Estado Social y Democrático de Derecho. Barcelona: Ariel.

Pontificia Universidad Javeriana. Consejo Académico. (2003) Documento aprobado por el Consejo Académico en su sesión del 4 de junio de 2003, Acta No. 040. Aprobado por el P. Rector el 11 de junio de 2003. Estudio de la Constitución e Instrucción Cívica. Pontificia Universidad Javeriana. Documento oficial.

Ramonet, I. (2004) Información, comunicación y globalización. El quinto poder. Revista Ciespal (88) Recuperado de: http://s3.amazonaws.com/academia.edu. documents/44690708/Sobre_el_quinto_poder_y_el_Observatorio_201604136329-7b1tfI.pdf?AWSAccessKeyId=AKIAIWOWYYGZ2Y53UL3A\&Expires $=14$ 92655764\&Signature=j\%2BFUnIx4209aoogdmyz7vZasCtA\%3D\&responsecontent-disposition=inline\%3B\%20filename\%3DSobre_el_quinto_poder_y_el_ Observatorio.pdf

Roa Roa, J. (2011) La libertad de expresión en las redes sociales y los casos de "school bullying". Recuperado de: http://www.scielo.org.co/pdf/rdes/n26/n26a09.pdf

Upegui Mejía, J. (2010) Libertad de expresión, redes sociales y derecho penal. Estudio del Caso Nicolás Castro. Revista Universidad Externado de Colombia. Pág.: 159 - 192.

\section{Normatividad internacional}

Asamblea General de las Naciones Unidas (1948) Declaración Universal de los Derechos Humanos. Recuperado de: https://www.unav.es/cdb/intderechos.pdf

- (1966) Pacto Internacional de Derechos Civiles y Políticos. Recuperado de: http:// www.ohchr.org/SP/Professionallnterest/Pages/CCPR.aspx

Comisión Interamericana de Derechos Humanos (1948) Declaración Americana de los Derechos y Deberes del Hombre. Novena Conferencia Internacional Americana. Bogotá. Recuperado de: http://www.oas.org/es/cidh/mandato/Basicos/declaracion.asp 
Consejo de Europa (1950) Convenio para la Protección de los Derechos Humanos y de las Libertades Fundamentales. Roma. Recuperado de: http://www.echr.coe.int/ Documents/Convention_SPA.pdf

Organización de los Estados Americanos (1969) Convención americana sobre derechos humanos (Pacto de San José) Conferencia Especializada Interamericana sobre Derechos Humanos. Costa Rica, 7 al 22 de noviembre de 1969. Recuperado de: https://www.oas.org/dil/esp/tratados_B-32_Convencion_Americana_sobre_ Derechos_Humanos.pdf

(1994) Informe anual de la Comisión Interamericana de Derechos Humanos 1994. Recuperado de: https://www.cidh.oas.org/annualrep/94span/indice.htm

\section{Jurisprudencia nacional}

Constitución política de Colombia. [Const.] (1991) 2da Ed. Legis.

Corte Constitucional (28 de octubre de 1993) Sentencia No. C-488/93 [MP VLADIMIRO NARANJO MESA].

Corte Constitucional, Sala Plena (12 de diciembre del 2000) Sentencia SU.1723/00 [MP ALEJANDRO MARTÍNEZ CABALLERO].

Corte Constitucional (26 de junio del 2002) Sentencia C-489/02 [MP RODRIGO ESCOBAR GIL].

Corte Constitucional, Sala Plena (2007) Sentencia T-391 de 2007 [MP MANUEL JOSÉ CEPEDA ESPINOSA].

Corte Constitucional, Sala Primera de Revisión de la Corte Constitucional (2010) Sentencia T-713/10 [MP MARÍA VICTORIA CALLE CORREA].

Corte Constitucional, Sala Quinta de Revisión de la Corte Constitucional (14 de diciembre del 2010) Sentencia T-1037/10 [MP JORGE IVÁN PALACIO PALACIO].

\section{Jurisprudencia Sistema Interamericano de Derechos Humanos}

Corte Interamericana de Derechos Humanos (2001) Caso "La Última Tentación de Cristo" (Olmedo Bustos y otros) Vs. Chile. Recuperado de: http://www.corteidh.or.cr/docs/ casos/articulos/Seriec_73_esp.pdf 
. (2001) Caso Ivcher Bronstein Vs. Perú. Recuperado de: http://www.corteidh.or.cr/ docs/casos/articulos/Seriec_74_esp.pdf

. (2004) Caso Herrera Ulloa Vs. Costa Rica. Recuperado de: http://www.corteidh.or.cr/ docs/casos/articulos/seriec_107_esp.pdf

. (2004) Caso Ricardo Canese Vs. Paraguay. Recuperado de: http://www.corteidh. or.cr/docs/casos/articulos/seriec_111_esp.pdf

. (2005) Caso Palamara Iribarne Vs. Chile. Recuperado de: http://www.corteidh.or.cr/ docs/casos/articulos/seriec_135_esp.pdf

. (2008) Caso Kimel vs. Argentina. Recuperado de: http://www.corteidh.or.cr/docs/ casos/articulos/seriec_177_esp.pdf

Informes Sistema Interamericano Derechos Humanos

Organización de los Estados Americanos (1994) Informe anual de la Comisión Interamericana de Derechos Humanos 1994. Recuperado de: https://www.cidh. oas.org/annualrep/94span/indice.htm

\section{Jurisprudencia Sistema Europeo de Derechos Humanos}

Tribunal Europeo de Derechos Humanos (1998) Case of Incal Vs. Turkey. Recuperado de: https://www.article19.org/resources.php/resource/2451/en/incal-v.-turkey

Tribunal Europeo de Derechos Humanos (1998) Case Bowman Vs. The United Kingdom. Recuperado de: http://www.tandfonline.com/doi/ abs/10.1080/13642989808406736?journalCode=fjhr20

\section{Artículos periodísticos}

Candelas, R. (2013) 1060 millones de usuarios en Facebook en el 2013. Merca2.0. Recuperado de: https://www.merca20.com/facebook-2013-1060-millones-deusuarios/ 